\title{
Science Academies' Refresher Course on Crystallography, Mineralogy, Igneous Petrology and Thermodynamics
}

26 December 2014 to 9 January 2015

at Indian Academy of Sciences, Jalahalli, Bangalore

Sponsored by Indian Academy of Sciences, Bangalore, Indian National Science Academy, New Delhi, The National Academy of Sciences, India, Allahabad

Studies on crystallography, mineralogy, petrology and thermodynamics are crucial to understand the nature and cause of diversity in rocks, the P-T condition of mineral and rock formation and the oxygen fugacity conditions and processes experienced by the rocks in reaching its present state. This Refresher Course will broadly cover important subjects like thermodynamics, phase equilibria relations, mineralogy and crystallography with conceptual advances in these fields.

Tentative List of Resource Persons: Professors Alok K Gupta (University of Allahabad); MRN Murthy (Indian Institute of Science, Bangalore); Nibir Mandal (Jadavpur University, Kolkata).

Course Director: Professor Alok K Gupta, University of Allahabad, Allahabad 211002.

Applications are invited from teachers involved in teaching undergraduate and postgraduate courses in Geology/Earth sciences. A few seats are also available for MSc students with outstanding records.

Interested applicants must submit their application ONLINE by clicking on the following link:

http://web-japps.ias.ac.in:8080/Refreshcourse/RCCT.jsp

A print copy of the application must also be sent by speed post forwarded by the head of the institution to: The Course Coordinator, Indian Academy of Sciences, C.V. Raman Avenue, Sadashivanagar P.O., Bangalore 560080.

Outstation candidates will be provided local hospitality and round trip bus/train (three- tier AC) fare by the shortest route.

For any other query, applicants can send an Email to: alok.krishna.gupta@gmail.com

Last date for receipt of applications: 15 October 2014.

Selected participants will be informed by: 22 October 2014 . 